\title{
A importância da procalcitonina associado aos pacientes em tratamento de covid-19
}

\author{
The importance of procalcitonin associated with patients undergoing covid-19 treatment \\ La importancia de la procalcitonina asociado a los pacientes sometidos a tratamiento com covid-19
}

Recebido: 09/04/2021 | Revisado: 17/04/2021 | Aceito: 04/05/2021 | Publicado: 19/05/2021

Sátira Alves silva
ORCID: https://orcid.org/0000-0002-7001-5828
Faculdade Santa Maria, Brasil
E-mail: alvessatira47@ gmail.com
Alexsandra Laurindo Leite
Faculdade Santa Maria, Brasil
ORCID: https://orcid.org/0000-0002-7322-4449
E-mail: alexsandralaurindo@ gmail.com
Dandara Dias Cavalcante Abreu
ORCID: https://orcid.org/0000-0003-1023-7522
Faculdade Santa Maria, Brasil
E-mail: dandaradias@ @otmail.com
Pierri Emanoel de Abreu Oliveira
ORCID: https://orcid.org/0000-0003-0575-0831
Faculdade Santa Maria, Brasil
E-mail: pierre.eao@ gmail.com

\section{Resumo}

Objetivo: Avaliar a importância da procalcitonina associado aos casos de covid-19. Metodologia: Trata-se de uma revisão literária com construção qualitativa, embasada em artigos pesquisados na base de dados do SciELO -Scientific Electronic Library Online, National Library of Medicine - PubMed e Biblioteca Virtual da Saúde - BVS. Tendo como filtro artigos científicos publicados entre os anos de 2016 a 2020, onde os critérios de inclusão serão: data de publicação, textos livremente disponíveis, entre os artigos previamente selecionados seus resumos serão lidos, e aqueles que não estiverem dentro dos resultados esperados serão excluídos. Serão utilizados os seguintes descritores: covid-19, procalcitonina e biomarcadores. Considerações finais: A realização desse estudo, demonstra que a dosagem da procalcitonina ajuda a distinguir pacientes graves críticos e moderados. Mostrou-se em estudos a evolução do parâmetro no setor laboratorial acerca da sua utilização como ferramenta elementar no setor da covid-19, afim de identificar precocemente pacientes com risco apresentável de coinfecção bacteriana e efeitos adversos, estratificandoos conforme o quadro clinico-laboratorial, logo esse prenuncio possibilita a destreza no tratamento terapêutico orientando o uso dos antibioterápicos, melhorando o prognóstico.

Palavras-chaves: Covid-19; Procalcitonina; Biomarcadores.

\begin{abstract}
Objective: To evaluate the importance of procalcitonin associated with cases of covid-19. Methodology: This is a literary review with qualitative construction, based on articles researched in the database of SciELO - Scientific Electronic Library Online, National Library of Medicine - PubMed and Virtual Health Library - VHL. Having as filter scientific articles published between the years 2016 to 2020, where the inclusion criteria will be: date of publication, freely available texts, among the articles previously selected, their abstracts will be read, and those that are not within the expected results will be excluded. The following descriptors will be used: covid-19, procalcitonin and biomarkers. Final considerations: The performance of this study demonstrates that the dosage of procalcitonin helps to distinguish critically ill and moderate severe patients. Studies have shown the evolution of the parameter in the laboratory sector regarding its use as an elementary tool in the covid-19 sector, in order to early identify patients with a presentable risk of bacterial co-infection and adverse effects, stratifying them according to the clinical and laboratory conditions, therefore, this foresight enables dexterity in therapeutic treatment, guiding the use of antibiotics, improving the prognosis.
\end{abstract}

Keywords: Covid-19; Procalcitonin; Biomarkers.

\section{Resumen}

Objetivo: Evaluar la importancia de la procalcitonina asociada a casos de covid-19. Metodología: Se trata de una revisión literária con construcción cualitativa, basada en artículos investigados en la base de datos de SciELO Scientific Electronic Library Online, National Library of Medicine - PubMed y Virtual Health Library - BVS. Teniendo como filtro los artículos científicos publicados entre los años 2016 a 2020, donde los criterios de inclusión serán: fecha de publicación, textos de libre disponibilidad, entre los artículos previamente seleccionados se leerán sus resúmenes, y se leerán aquellos que no se encuentren dentro de los resultados esperados. ser excluido. Se utilizarán los 
siguientes descriptores: covid-19, procalcitonina y biomarcadores. Consideraciones finales: La realización de este estudio demuestra que la dosis de procalcitonina ayuda a distinguir a los pacientes críticamente enfermos de los de gravedad moderada. Estudios han evidenciado la evolución del parámetro en el sector laboratorio en cuanto a su uso como herramienta elemental en el sector covid-19, con el fin de identificar precozmente a pacientes con riesgo presentable de coinfección bacteriana y efectos adversos, estratificándolos según condiciones clínicas y de laboratorio., por tanto, esta previsión permite destreza en el tratamiento terapéutico, orientando el uso de antibióticos, mejorando el pronóstico.

Palabras clave: Covid-19; Procalcitonina; Biomarcadores.

\section{Introdução}

O SARS-CoV 2 integrante da família coronaviridae, foi documentado pela primeira vez em Wuham na China sendo considerado o terceiro corona vírus humano zoonótico. Seu genoma foi decodificado permitindo o conhecimento deste material genético, que sugeriu a existência de um processo recombinante e de um potencial hospedeiro intermediário (Cheng, et al., 2020).

A covid-19 comporta-se como um processo infeccioso viral que atingiu patamares pandêmicos de forma abrupta, profissionais e pesquisadores foram enlaçados de maneira inesperada diante dos aspectos clínicos, epidemiológicos, virológicos e laboratoriais. O curso da doença na sociedade se categoriza nos casos leves, sendo esses sintomáticos brandos ou assintomáticos, e os casos graves onde se observa o desenvolvimento da síndrome do desconforto respiratório agudo (SDRA), necessitando assim de internamento hospitalar (Henry, et al., 2020).

Avalia-se de maneira concisa as alterações nos parâmetros hematológicos e de marcadores, com intuito de compreender o comportamento do vírus no organismo e de embargar a deterioração clínica do paciente. Destaca-se o papel dos biomarcadores nesse âmbito com ênfase na procalcitonina (PCT), a mesma em estudos vem demonstrando sua aplicabilidade nos casos graves de covid-19 complementando demais análises, garantindo assim uma visão real do prognóstico desse individuo (Huang, et al., 2020).

A procalcitonina é um precursor do hormônio calcitonina que em circunstâncias normais é produzida pelas células C da tireoide, contudo em situações de desordem inflamatória e infecciosa os seus níveis circulantes são elevados em decorrência a uma fabricação extratireoidiana, após um estimulo indutivo. Sua elevação é considerada um preditivo para possível coinfecção bacteriana, e até descarte na admissão de que esse processo esteja instalado no organismo do paciente (Huang, et al., 2020).

Dosagens de PCT em níveis acima de 0,5ng são interpretados como alterado, correlacionando com o estado clinico do paciente e seus demonstrativos nos exames hematológicos, de imagem, e os teste de diagnóstico do covid-19, podendo ser considerado como um valor preditivo para quadros de septicemia, choque séptico e risco de mortalidade (Frater, et al, 2020).

Segundo a Agência nacional de saúde suplementar (2020) o PCT é considerado um marcador promissor, incluído no rol de exames que auxiliam no diagnóstico e tratamento da covid-19 pela Resolução Normativa $n^{\circ} 457$ do Diário oficial da união, o que possibilita estratificar o risco desses pacientes precocemente de modo que sua vida seja preservada e os óbitos evitados.

\section{Metodologia}

A metodologia utilizada trata-se de uma revisão de literatura com construção qualitativa, feita por meio de base de dados como o Scientific Electronic Library online - SCIELO, National Library of Medicine - PubMed e Biblioteca Virtual em Saúde - BVS, e em consociação as palavras chaves " covid-19", " procalcitonina" e " biomarcadores".

A revisão da literatura viabiliza uma recopilação de informações, estabelecendo conexão do saber existente e a comunidade cientifica afim de expandir a área estudada. Esse tipo de estudo é uma abordagem ampla, com caráter 
críticolcientifico, incorporando analises da temática conforme os seus propósitos peculiares delineando a formação de uma nova visão. (Moreira, 2004)

A análise literária visa sintetizar o conhecimento existente em pretensão da sua compreensão, assim como minimizar as inquietações possibilitando contribuir junto a sociedade cientifica e otimizar os resultados pesquisados. (Mendes, et al., 2008).

Após a definição do tema, foi feito um agrupamento da literatura correspondente a temática durante agosto de $2020 \mathrm{e}$ maio de 2021, sendo utilizados artigos científicos de revistas. Os critérios de inclusão: data de publicação, textos livremente disponíveis, entre os artigos previamente selecionados seus resumos serão lidos, e aqueles que não estiverem dentro dos resultados esperados serão excluídos. Para os critérios de exclusão foram selecionados artigos que se repetiam nas bases de dados e artigos que não contemplavam o conteúdo trabalhado.

Os artigos encontrados foram organizados e lidos integralmente garantindo uma epítome plena do objeto estudado. Foi utilizado como recurso metodológico um fluxograma que permitiu filtrar os artigos selecionados, visualizando a sua totalização após o emprego dos critérios de seleção.

Figura 1: Fluxograma da pesquisa e seleção dos estudos para a revisão integrativa.

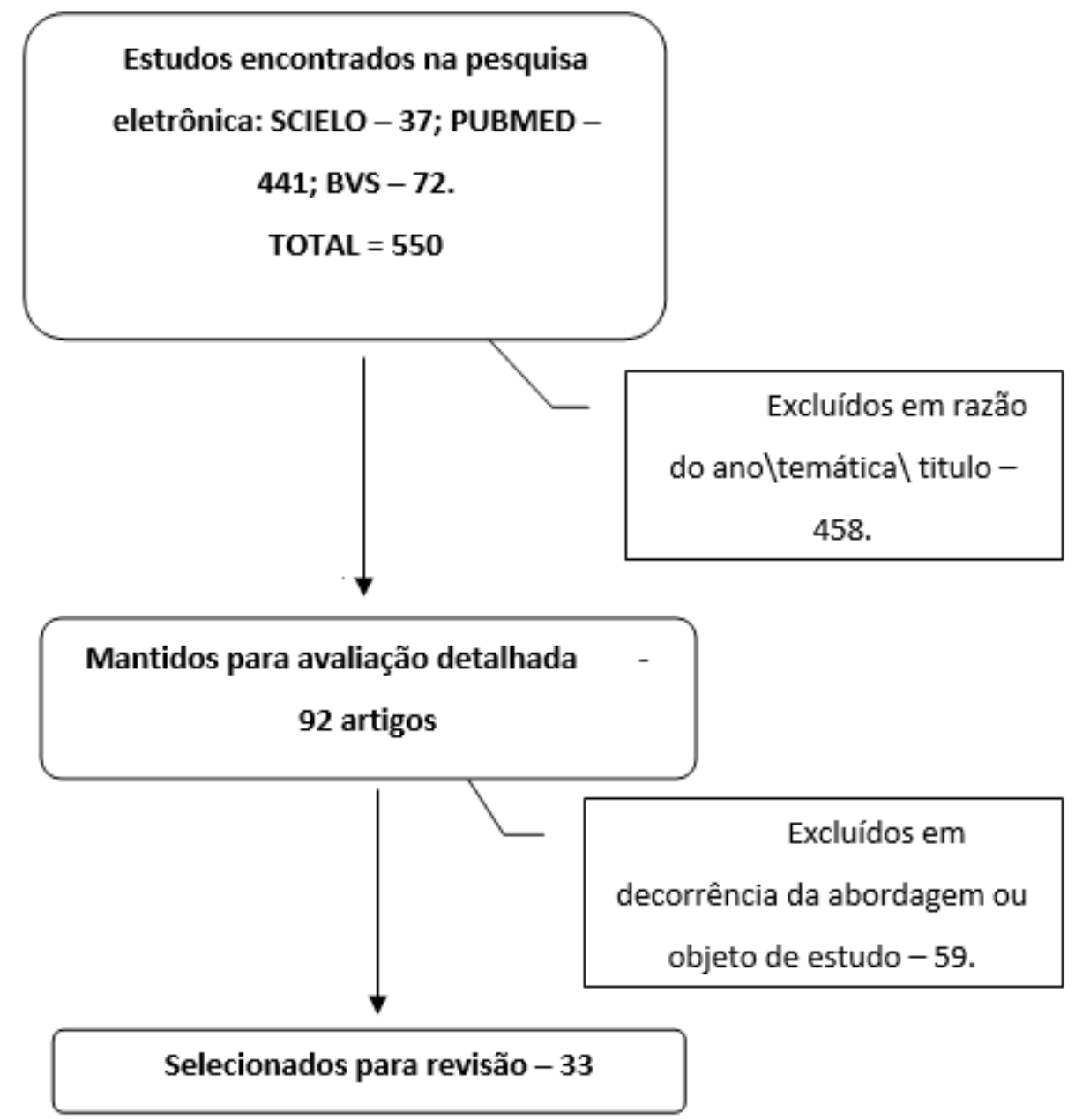

Fonte: Autores.

\section{Resultados}

Os artigos contemplados fomentam uma discussão sobre o biomarcador procalcitonina e sua importância no tratamento dos pacientes com covid-19. 
Visando nortear o entendimento acerca dos artigos estudados, caracterizou-se os estudos de acordo com o seu ano, o autor, título e os resultados obtidos contemplando assim o objeto de pesquisa, somatizando para uma construção pertinente da literatura. Contiguo a isso, prosperar argumentações fidedignas e meritórias conforme o exposto no Quadro 1.

Quadro 1: Fluxograma da pesquisa e seleção dos estudos para a revisão integrativa.

\begin{tabular}{|c|c|c|c|}
\hline Ano & Autor (es) & Título & Resultados \\
\hline 22020 & Amawi, et al; & $\begin{array}{l}\text { Pandemia de covid-19: uma visão } \\
\text { geral da epidemiologia, patogênese, } \\
\text { diagnósticos e potenciais vacinas e } \\
\text { terapêuticas }\end{array}$ & $\begin{array}{l}\text { Avanços terapêuticos e do desenvolvimento de agentes } \\
\text { imunizantes com grau relevante para o vírus SARS-COV-2, } \\
\text { assim como os seus aspectos comportamentais. Estudos em } \\
\text { fase laboratorial, clinico e in vitro. }\end{array}$ \\
\hline 22020 & Casadevall & $\begin{array}{l}\text { A opção de soros convalescentes } \\
\text { para conter covid-19 }\end{array}$ & $\begin{array}{l}\text { A utilização pode ser realizada em pacientes sintomáticos } \\
\text { reduzindo a severidade do quadro viral. }\end{array}$ \\
\hline 22020 & Cheng, et al; & $\begin{array}{l}\text { Novo coronavírus: onde estamos e o } \\
\text { que sabemos }\end{array}$ & $\begin{array}{l}\text { A uma variação da susceptibilidade de acordo com o gênero } \\
\text { do indivíduo e suas comorbidades, atingindo diversas faixas } \\
\text { etárias. }\end{array}$ \\
\hline 22020 & $\begin{array}{l}\text { Cerqueira, et } \\
\text { al; }\end{array}$ & $\begin{array}{l}\text { Principais métodos diagnósticos da } \\
\text { covid-19: recomendações e } \\
\text { perspectivas }\end{array}$ & $\begin{array}{l}\text { Em decorrência da emergencialidade os testes aprovados } \\
\text { contemplaram a RDC } n^{\circ} 348 \text {. Padrão ouro no diagnóstico o } \\
\text { RT-PCR, seguido da metodologia sorológica e do teste } \\
\text { rápido pelo método imunocromatográfico, é plausível a } \\
\text { associação de metodologias inclusive de exames de imagem. }\end{array}$ \\
\hline 22020 & $\begin{array}{l}\text { Da Silveira } \\
\text { Cespedes, et } \\
\text { al; }\end{array}$ & $\begin{array}{l}\text { SARS-CoV-2: uma revisão para o } \\
\text { clínico }\end{array}$ & $\begin{array}{l}\text { Uma maior transmissibilidade e mortalidade, com } \\
\text { características clinicas de sintomas gripais. Terapêutica de } \\
\text { suporte grave hidroxicloroquina, azitromicina ou remdesevir } \\
\text { contudo, necessita de maiores avanços neste setor. }\end{array}$ \\
\hline 22020 & Feng, et al; & $\begin{array}{l}\text { Uso racional de máscaras faciais na } \\
\text { pandemia covid-19 }\end{array}$ & $\begin{array}{l}\text { O uso das máscaras faciais preveni o processo de } \\
\text { contaminação, protegendo do contato com aerossóis } \\
\text { infectados. }\end{array}$ \\
\hline 22020 & $\begin{array}{l}\text { Fernandes } \\
\text { silva, et al; }\end{array}$ & $\begin{array}{l}\text { Epidemiologia da covid-19: } \\
\text { comparação entre boletins } \\
\text { epidemiológicos }\end{array}$ & $\begin{array}{l}\text { Os casos de covid-19 demostraram maior incidência na } \\
\text { região sudeste, com frequência de comorbidade cardiopática, } \\
\text { seguindo a faixa etária } 60+\text { e prevalência no gênero } \\
\text { masculino. }\end{array}$ \\
\hline 22020 & $\begin{array}{l}\text { Folegatti, et } \\
\text { al; }\end{array}$ & $\begin{array}{l}\text { Segurança e imunogenicidade da } \\
\text { vacina ChAdOx1 nCoV-19 contra } \\
\text { SARS-CoV-2: um relatório } \\
\text { preliminar de um ensaio clínico } \\
\text { randomizado controlado de fase } 1 / 2 \text {, } \\
\text { simples-cego }\end{array}$ & $\begin{array}{l}\text { Relatado após recebimento da vacina ChAdOx } 1 \mathrm{nCoV}-19 \text {, } \\
\text { fadiga, dor de cabeça, dor muscular, febre e mal estar, } \\
\text { reações amenizadas com o uso do paracetamol e moderação } \\
\text { na reatogenicidade na segunda dose administrada, } \\
\text { considerando-a segura. }\end{array}$ \\
\hline 22020 & Frater, et al; & $\begin{array}{l}\text { Covid - } 19 \text { e o laboratório de } \\
\text { hematologia clínica }\end{array}$ & $\begin{array}{l}\text { Pacientes com covid-19 apresentaram linfopenia, } \\
\text { leucocitose, neutrofilia e trombocitopenia, estes interpretados } \\
\text { como indicadores de gravidade desta infecção, associados } \\
\text { aos teste de coagulação. Biomarcadores alteraram-se } \\
\text { caracterizando a severidade do quadro como a PCT sugestivo } \\
\text { de coinfecção, dentre outros como PCR, LDH, Dímero D, } \\
\text { bilirrubina etc. Fomentando a importância de suas dosagens. }\end{array}$ \\
\hline
\end{tabular}




\begin{tabular}{|c|c|c|c|}
\hline 22020 & $\mathrm{Fu}$, et al; & $\begin{array}{l}\text { Lesão renal aguda e terapia de } \\
\text { substituição renal em covid-19: uma } \\
\text { revisão sistemática e meta-análise }\end{array}$ & $\begin{array}{l}\text { Pacientes com covid-19 desenvolveram complicações } \\
\text { lesional renal aguda, tal evento está relacionado com } \\
\text { características físico-patológicas dos indivíduos. }\end{array}$ \\
\hline 22020 & Henry, et al; & $\begin{array}{l}\text { Anormalidades laboratoriais em } \\
\text { crianças com doença coronavírus } \\
\text { leve e grave } 2019 \text { (covid-19): uma } \\
\text { análise e revisão agrupadas }\end{array}$ & $\begin{array}{l}\text { Presença de irregularidade em parâmetros laboratoriais nos } \\
\text { casos de covid pediátrica; Predominância em neutrofilia, } \\
\text { leucopenia, linfopenia com elevação da Procalcitonina tendo } \\
\text { como hipótese a presença de infecção secundária bacteriana } \\
\text { - deve ser realizado a dosagem serial; Aumento de CK-MB, } \\
\text { LDH e PCR. }\end{array}$ \\
\hline 22020 & Huang, et al; & $\begin{array}{l}\text { Proteína C reativa, procalcitonina, } \\
\text { dímero D e ferritina na doença } \\
\text { coronavírus grave-2019: uma meta- } \\
\text { análise }\end{array}$ & $\begin{array}{l}\text { Elevação da PCR, PCT, Dímero D e ferritina, o resultado } \\
\text { desses parâmetros considerados acima do limite normal foi } \\
\text { considerado mau prognostico, relacionados aos quadros } \\
\text { severos com desenvolvimento de SDRA. }\end{array}$ \\
\hline 22020 & Ji, et al; & $\begin{array}{l}\text { Transmissão cruzada de espécies do } \\
\text { coronavírus recém-identificado } \\
\text { 2019-nCoV }\end{array}$ & $\begin{array}{l}\text { Existem inúmeras variações genéticas do coronavírus, } \\
\text { evolutivamente } 272 \text {, o SARS-CoV-2 é o causador da covid- } \\
\text { 19; O vírus tem potencias hospedeiros, o que respalda o } \\
\text { processo de transmissão cruzada. }\end{array}$ \\
\hline 22020 & $\begin{array}{l}\text { Kunutsor, et } \\
\text { al; }\end{array}$ & $\begin{array}{l}\text { Manifestações hepáticas e } \\
\text { complicações de covid-19: uma } \\
\text { revisão sistemática e meta-análise }\end{array}$ & $\begin{array}{l}\text { A irregularidade apresentada nas enzimas hepáticas em } \\
\text { âmbito laboratorial são coerentes com o desenvolvimento de } \\
\text { lesão hepática aguda, sendo um fator de risco para evolução } \\
\text { de paciente de infectados. }\end{array}$ \\
\hline 22020 & Li Q, et al; & $\begin{array}{l}\text { Dinâmica de transmissão inicial em } \\
\text { Wuhan, China, da nova pneumonia } \\
\text { infectada com coronavírus }\end{array}$ & $\begin{array}{l}\text { Devido ao aumento abrupto de pessoas infectadas, a via } \\
\text { principal de transmissão é pessoa a pessoa devido ao contato } \\
\text { próximo, tempo médio de incubação } 5,2 \text { dias. }\end{array}$ \\
\hline 22020 & $\mathrm{Li}$, et al; & $\begin{array}{l}\text { O potencial neuroinvasivo de SARS- } \\
\text { CoV2 pode desempenhar um papel } \\
\text { na insuficiência respiratória de } \\
\text { pacientes com covid-19. }\end{array}$ & $\begin{array}{l}\text { Devido a afinidade do vírus por receptores ACE2, ocorre o } \\
\text { seu tropismo para outros tecidos desencadeando neuro } \\
\text { sintomas no caso de acometimento neurológico. }\end{array}$ \\
\hline 22020 & Lima; & $\begin{array}{l}\text { Informações sobre a nova doença } \\
\text { coronavírus (covid-19) }\end{array}$ & $\begin{array}{l}\text { Os aspectos patológicos são amplos semelhantes a quadros } \\
\text { gripais contudo, o seu desfecho é uma particularidade de } \\
\text { cada indivíduo infectado, padrões de exames de imagem } \\
\text { podem auxiliar na compreensão da infecção. }\end{array}$ \\
\hline 22020 & Madjid, et al; & $\begin{array}{l}\text { Efeitos potenciais dos coronavírus no } \\
\text { sistema cardiovascular: Uma revisão }\end{array}$ & $\begin{array}{l}\text { A presença de fatores secundários relacionados ao sistema } \\
\text { cardiovascular podem culminar do desenvolvimento de } \\
\text { complicações cardíacas, associado a ampla distribuição da } \\
\text { ACE2 nesses tecidos, essas lesões causam miocardite. }\end{array}$ \\
\hline 22020 & $\begin{array}{l}\text { Mahtani, et } \\
\text { al; }\end{array}$ & $\begin{array}{l}\text { Quais são as evidências de } \\
\text { distanciamento social durante } \\
\text { pandemias globais? Um rápido } \\
\text { resumo do conhecimento atual. }\end{array}$ & $\begin{array}{l}\text { Medidas foram tomadas na tentativa de conter o avanço da } \\
\text { contaminação; O distanciamento social apresentou sua } \\
\text { notória contribuição para o momento emergencial, atitudes } \\
\text { mais rígidas como Lockdows e isolamento dos suspeitos. }\end{array}$ \\
\hline 22020 & Mao, et al; & $\begin{array}{l}\text { Manifestações neurológicas de } \\
\text { pacientes hospitalizados com doença } \\
\text { do coronavírus de } 2019 \text { em Wuhan, } \\
\text { China. }\end{array}$ & $\begin{array}{l}\text { Pessoas acometidas pelo covid apresentaram manifestações } \\
\text { neurológicas, com incidência na perca do olfato e paladar. }\end{array}$ \\
\hline
\end{tabular}




\begin{tabular}{|c|c|c|c|}
\hline 22020 & $\begin{array}{l}\text { Mc intosh, et } \\
\text { al; }\end{array}$ & $\begin{array}{l}\text { Doença de coronavírus } 2019 \text { (covid- } \\
\text { 19) }\end{array}$ & $\begin{array}{l}\text { Os aspectos de comportamento viral variam, e não se } \\
\text { delimitam; Seu desenvolvimento no individuo é condizente } \\
\text { com sua resposta imunológica. }\end{array}$ \\
\hline 22020 & $\begin{array}{l}\text { Ministério da } \\
\text { saúde }\end{array}$ & Boletim epidemiológico & $\begin{array}{l}\text { Dados epidemiológicos da covid na semana de } 30.08 \text { a } \\
05.09 ; 4.123 .000 \text { casos e } 126.203 \text { óbitos. }\end{array}$ \\
\hline 22020 & $\begin{array}{l}\text { Nascimento, } \\
\text { et al; }\end{array}$ & $\begin{array}{l}\text { Complicações neurológicas } \\
\text { associadas ao SARS-CoV-2 (covid- } \\
\text { 19) no Brasil: Organização do grupo } \\
\text { NEUROCOVID-RIO e achados } \\
\text { Preliminares. }\end{array}$ & $\begin{array}{l}\text { Casos graves de covid-19 tem probabilidade maior de } \\
\text { acometimento ao SNC. }\end{array}$ \\
\hline 22020 & Netto, et al; & $\begin{array}{l}\text { Epidemiologia do surto de doença } \\
\text { por coronavírus (covid-19). }\end{array}$ & $\begin{array}{l}\text { Devido a velocidade da propagação a doença tornou-se um } \\
\text { problema mundial de saúde caracterizando assim uma } \\
\text { Pandemia; Em território brasileiro o número permanece em } \\
\text { crescente exponencial. }\end{array}$ \\
\hline 22020 & Nunes, et al; & $\begin{array}{l}\text { Exames diagnósticos e manifestações } \\
\text { clinicas da covid-19 em crianças: } \\
\text { revisão integrativa. }\end{array}$ & $\begin{array}{l}\text { Crianças em grande parte são assintomáticas ou manifestam } \\
\text { sintomas leves, contudo a preconização dos diagnósticos } \\
\text { nessa faixa etária é importante, podendo reduzir o curso } \\
\text { clinico da doença e o tempo em unidade hospitalar. }\end{array}$ \\
\hline 22020 & $\begin{array}{l}\text { Siemieniuk, et } \\
\text { al; }\end{array}$ & $\begin{array}{l}\text { Tratamentos medicamentosos para } \\
\text { covid-19: revisão sistemática viva e } \\
\text { meta-análise de rede }\end{array}$ & $\begin{array}{l}\text { O tratamento é sobretudo sintomático, estudos sobre terapias } \\
\text { com Azitromicina, hidroxicloroquina, lopinavirłritonavir, } \\
\text { interferon-beta, não demostraram ação relevante nos casos de } \\
\text { terapêutica para covid-19. }\end{array}$ \\
\hline 22020 & Terpos, et al; & $\begin{array}{l}\text { Achados hematológicos e } \\
\text { complicações de covid-19 }\end{array}$ & $\begin{array}{l}\text { Em âmbito hematológico observou-se linfocitopenia, } \\
\text { trombocitopenia e leucopenia; Casos graves tiveram aumento } \\
\text { no demonstrativo dos biomarcadores (CRP, ferritina e } \\
\text { Procalcitonina) compatíveis com o nível } \\
\text { inflamatóriolinfeccioso da doença; Pacientes com PCT > 0,5 } \\
\text { ng\ml estavam associados a indigência de UTI e ao risco de } \\
\text { mortalidade; A covid-19 também apresenta o } \\
\text { desenvolvimento da hipercoagulabilidade do sangue. }\end{array}$ \\
\hline 22020 & Turci, et al; & $\begin{array}{l}\text { A Vigilância Epidemiológica diante } \\
\text { do Sars-Cov-2: desafios para o SUS } \\
\text { e a Atenção Primária à Saúde }\end{array}$ & $\begin{array}{l}\text { A abrangência de casos contaminados pelo vírus SARS- } \\
\text { CoV- } 2 \text { evidencia a existência de subnotificação; O SUS em } \\
\text { conjunto a Vigilância epidemiológica executam o papel de } \\
\text { rastreio, notificação, acompanhamento dos casos e } \\
\text { orientação de medidas preventivas. }\end{array}$ \\
\hline 22020 & $\begin{array}{l}\text { Wei Zhang, et } \\
\text { al; }\end{array}$ & $\begin{array}{l}\text { Investigação molecular e sorológica } \\
\text { de pacientes infectados com nCoV } \\
\text { 2019: implicação de múltiplas rotas } \\
\text { de eliminação }\end{array}$ & $\begin{array}{l}\text { A detecção do vírus pode ser realizada por método } \\
\text { sorológico e molecular, utilizado o swab e fluidos corporais. }\end{array}$ \\
\hline 22020 & Xavier, et al; & $\begin{array}{l}\text { Covid-19: manifestações clínicas e } \\
\text { laboratoriais na Infecção pelo novo } \\
\text { coronavírus }\end{array}$ & $\begin{array}{l}\text { Sua sintomatologia é semelhante a outras infecções virais } \\
\text { que causam quadros gripais; A confirmação da infecção pode } \\
\text { ser evidenciada pelo RT-PCR; A dosagem seriada da } \\
\text { Procalcitonina teve aptidão em prenunciar a existência de } \\
\text { processo infeccioso bacteriano - sugestivo de coinfecção. }\end{array}$ \\
\hline
\end{tabular}




\begin{tabular}{|c|c|c|c|}
\hline 22020 & Yan, et al; & $\begin{array}{l}\text { Os primeiros } 75 \text { dias do novo surto } \\
\text { de coronavírus (SARS-CoV-2): } \\
\text { avanços recentes, prevenção e } \\
\text { tratamento }\end{array}$ & $\begin{array}{l}\text { Evidente o caráter emergente, contagioso e letal do vírus, } \\
\text { necessitando o cumprimento de cuidados preventivos; } \\
\text { Gradativamente avalia-se um plano terapêutico eficaz. }\end{array}$ \\
\hline 22020 & Zhang, et al; & $\begin{array}{l}\text { Transmissão secundária da doença } \\
\text { por coronavírus de pessoas pré- } \\
\text { sintomáticas, China }\end{array}$ & $\begin{array}{l}\text { Assintomáticos aderem a capacidade de transmissão; O } \\
\text { contato com indivíduos em qualquer grau infeccioso pode } \\
\text { levar ao contágio, o cuidado estende-se aos indivíduos em } \\
\text { isolamento. }\end{array}$ \\
\hline 22020 & Zheng, et al; & Covid-19 e o sistema cardiovascular & $\begin{array}{l}\text { Complicações cardiovasculares foram observadas em } \\
\text { indivíduos de covid-19, acredita-se que esteja relacionado } \\
\text { com a presença da enzima conversora de angiotensina } \\
\text { (ACE2); Verificou-se a presença de lesão miocárdica; A } \\
\text { evolução da clínica associa-se com a presença de lesões pré- } \\
\text { existentes, assim como o monitoramento de cronicidade } \\
\text { desses eventos Pós-covid. }\end{array}$ \\
\hline 22020 & Zhu, et al; & $\begin{array}{l}\text { Um novo coronavírus de pacientes } \\
\text { com pneumonia na China, } 2019\end{array}$ & $\begin{array}{l}\text { A confirmação de contágio pelo covid-19 é principalmente } \\
\text { por via laboratorial, verificando a presença do vírus, a } \\
\text { produção de anticorpos e o sequenciamento do seu material } \\
\text { genético; O isolamento viral pode ser reproduzido com o } \\
\text { material de lavagem broncoalveolar, demostrando após a } \\
\text { Tomografia de tórax a presença de infecção pneumática. }\end{array}$ \\
\hline
\end{tabular}

Fonte: Autores.

Gráfico 1: Apresenta os artigos selecionados de acordo com o ano.

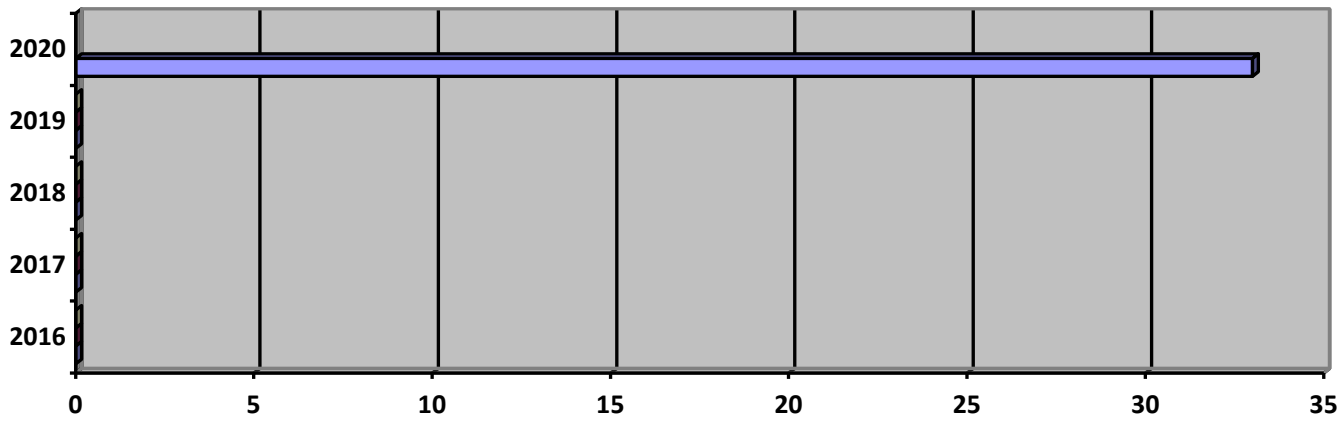

Fonte: Primária de pesquisa literária.

Ao realizar o estudo dos artigos selecionados cultivou-se o aprendizado com respeito a temática pretendida, e assim edificando o trabalho. As pesquisas eleitas foram divididas em ano de publicação, conforme o gráfico 1.0 ano com maior publicação foi o ano de 2020, correspondendo a 100\% do total ( $\mathrm{n}=33$ ), seguido dos anos 2016 a 2019 , onde não foram encontrados artigos publicados que contemplassem a temática a ser estudada $(\mathrm{n}=0)$, visto que o conteúdo pesquisado tem índole atual vigente do ano 2020, devido ao decurso da pandemia causado pelo SARS-CoV-2 que explicitou a indigência de pesquisas nessa área circundando seus aspectos 


\section{Discussões}

A covid-19 desenvolveu-se sob circunstâncias emergenciais devido a rapidez de sua propagação, o vírus acomete no precípuo o sistema respiratório agudamente. A contingência é excêntrica de cada indivíduo infectado, variável conforme a resposta imunológica frente ao patógeno. A manifestação clinica possui aspectos similares com quadros gripais, a princípio sintomas leves contudo esse cenário pode modificar-se abruptamente necessitando de agilidade na redução dessa descompensação prognóstica. (Liu, et al, 2020)

Procalcitonina é encontrada em níveis fisiológicos no organismo, no ambiente infeccioso viral o seu valor é normatizado. Em meio aos aspectos comportamentais do SARS-CoV-2, compreende-se que sua designação instaura junto a resposta inflamatória sendo um estimulo a sua produção e sinal de alerta para o paciente. (Liu, et al, 2020)

Adversidades da covid-19 tencionam a precisão em conter o avanço da doença, a procalcitonina quando apresentada em um valor > 0,05 $\mathrm{ng} \backslash \mathrm{ml}$ é interpretado como alterado e associado a possível existência de infecção bacteriana - o fato tem potencial de estar adjunto a infecção dirigente de origem viral sendo assim sugestivo de panorama coinfectivo. Biomarcadores tem funcionalidade múltipla nas doenças investigadas, utilizado como fonte de monitoramento, diagnóstico e orientação, logo as características fisiopatológicas da covid-19 reafirmam a importância da análise desses parâmetros auxiliando no entendimento da doença. (Savio, et al, 2021; Garg, et al, 2020)

O comportamento da PCT em situações patológicas bacterianas decorre da sua elevação, possibilitando avaliar a evolução clinica atual. No contexto viral sua produção é suprimida pela IFN- $\alpha$, evidenciando a causa do seu aumento - uma infecção secundária de causa bacteriana, que por vez induz a produção de procalcitonina extratireoidiana em virtude da presença estimulatória de citocinas e TNF- $\alpha$. Esse cenário coinfectivo é considerado um agravante para saúde do indivíduo, e quando não se intervém pode evoluir para sepse, choque séptico e óbito, logo a Procalcitonina mostrou-se ser um biomarcador prenuncioso dessa progressão. (Savio, 2021)

Pacientes com covid-19 que apresentaram a procalcitonina alta tinham maior risco de mortalidade, sinalizando aos profissionais o quadro coinfectivo e sua respectiva extensão, respaldado em características de sensibilidade e especificidade para o contexto inserido logo, esse resultado levará a antecipação terapêutica melhorando o prognóstico do indivíduo. Orientase a dosagem sérica podendo ser executada de modo seriado afim de verificar a efetividade do tratamento, estratificar o risco dos pacientes em admissão e na UTI. Apesar do seu valor ser normal em indivíduos com sintomas leves da covid-19, a sua funcionalidade é notável neste meio. (Liu, et al, 2020)

A análise desse marcador dentro do contexto infecciosolinflamatório propiciado pelo SARS-CoV-2 conseguiu se sobressair demostrando precisão ao prenunciar o cenário crítico do paciente, conduzindo a antibioticoterapia otimizando a recuperação, restringindo o avanço da doença. (Zare, et al, 2020)

\section{Considerações Finais}

A realização desse estudo, demonstra que a dosagem da procalcitonina ajuda a distinguir pacientes graves críticos e moderados. Mostrou-se em estudos a evolução do parâmetro no setor laboratorial acerca da sua utilização como ferramenta elementar no setor da covid-19, afim de identificar precocemente pacientes com risco apresentável de coinfecção bacteriana e efeitos adversos, estratificando-os conforme o quadro clinico-laboratorial, logo esse prenuncio possibilita a destreza no tratamento terapêutico orientando o uso dos antibioterápicos, melhorando o prognóstico.

Logo a procalcitonina conforme o seu resultado sinaliza a extensão do cenário infeccioso bacteriano, que quando não diagnosticado e tratado a tempo poderá evoluir para uma sepse e consequentemente suas complicações como choque séptico 
elou óbito, esse cenário representa hoje a principal causa de morte nas unidades de terapia intensiva, podendo ser antevista em conexo ao cenário clinico, as metodologias utilizadas, tendo cada caso um olhar ímpar.

Faz-se necessário à amplificação da funcionalidade desse marcador dentro da covid-19 com foco e inclusão do mesmo nos setores de diagnósticoltratamento, evidenciando a sua valia na progressão clinica dos pacientes, que pode ser vista em estudos científicos capacitando-a como útil. Profissionais da saúde, pesquisadores científicos, devem atualizar-se e trabalhar de forma multidisciplinar buscando avanços benéficos para os pacientes infectados.

Embora a extensão desse estudo, visto a relevância do conteúdo e sua inerente contribuição a sociedade, faz-se necessário uma contínua análise dos dados e expansão das pesquisas sobre esta temática, com intuito de otimizar o manejo clinico dos indivíduos com covid-19 por meio do conhecimento da funcionalidade deste biomarcador, por parte dos acadêmicos, cientistas e profissionais da saúde.

\section{Agradecimentos}

Agradeço inicialmente a Deus por me fortalecer dia a dia na construção dessa caminhada, pela fé inabalável, me concedendo saúde e mostrando-me que o proposito desta vida é servir ao próximo.

Agradeço aos meus pais, pelo suporte dado durante a vida acadêmica, por me impulsionar a ser uma profissional humana, confiando no meu potencial sendo o meu alicerce de ensinamentos, assim como ao meu irmão pela colaboração nesse processo.

A minha avô e ex-professora, que foi uma mola propulsora na minha formação e símbolo de fé, de oração, uma incentivadora dos meus sonhos. Em seu nome agradeço aos demais familiares.

A meu parceiro na vida, João Pedro, a sua chegada nesse percurso avivou os meus dias, agradeço pela cumplicidade, paciência, por mesmo sem perceber conseguir acalmar os meus momentos de ansiedade, pelo carinho e amor.

Aos amigos, cito a pessoa de Ana Beatriz, Renata Layanna e Mayanna, a vocês agradeço pela amizade, pelo apoio nos momentos de alegria e pelo acolhimento nas incertezas, por trazerem felicidade ao meu coração.

Ao meu avô Doca (in memoriam), agradeço pelo cuidado, o amor externado, valores ensinados e recordações que construímos, sei que está feliz com o alcance deste sonho.

qualificação, sendo aporte para formação de profissionais humanizados e capacitados. Estendo esse agradecimento a Orientadora, pessoa essencial na elaboração deste trabalho acadêmico, grata pela sua sensibilidade, por acreditar nessa proposta, incentivando a busca pelo estudo e despertando o amor pela profissão, mostrando que somos capazes.

\section{Referências}

Amawi, H., I Abu Deiab, G., AA Aljabali, A., Dua, K., \& M Tambuwala, M. (2020, May 12). Pandemia de COVID-19: uma visão geral da epidemiologia, patogênese, diagnósticos e potenciais vacinas e terapêuticas. ENTREGA TERAPEEUTICA, 11(4), 245-268.

Casadevall, A., \& Pirofski, L. (2020, March 13). A opção de soros convalescentes para conter COVID-19. J Clin Invest, $1545-1548$.

Cheng, Z. J., \& Shan, J. (2020, February 18). Novo coronavírus 2019: onde estamos e o que sabemos. Infecção, 48, $155-163$.

Costa Nogueira Cerqueira, L., Rangel da Silva Garcia, K., Cardoso Trugilho, F., Wilnes Simas Pereira, A., Wilnes Simas Pereira, B., Messias Gandra, R., \& Barcellos Oliveira Koeppe, G. (2020). PRINCIPAIS MÉTODOS DIAGNÓSTICOS DA COVID-19: recomendações e perspectivas. Saúde Coletiva (Barueri), 10(54), 2633-2638. https://doi.org/10.36489/saudecoletiva.2020v10i54p2633-2638

Cespedes, Mateus da Silveira, \& Souza, José Carlos Rosa Pires de. (2020). Sars-CoV-2: Uma atualização clínica - II. Revista da Associação Médica Brasileira, 66 (4), 547-557. Epub 15 de junho de 2020. https://doi.org/10.1590/1806-9282.66.4.547

Feng, s., shen, c., xia, n., song, w., Fan, M., \& Cowling, B. J. (2020, March 20). Uso racional de máscaras faciais na pandemia COVID-19. The Lancet. Respiratory medicine, 8(5), 434-436.

Fernandes Silva, D., \& Cunha de Oliveira, M. L. (2020). Epidemiologia da COVID-19: comparação entre boletins epidemiológicos. Comunicação Em Ciências Da Saúde, 31(Suppl 1), 61-74. https://doi.org/10.51723/ccs.v31iSuppl 1.661 
Folegatti, P. M., Ewer, K. J., Aley, P. K., Angus, B., Becker, S., Belij-Rammerstorfer, S., Bellamy, D., Bibi, S., Bittaye, M., Clutterbuck, E. A., Dold, C., Faust, S. N., Finn, A., Flaxman, A. L., Hallis, B., Heath, P., Jenkin, D., Lazarus, R., Makinson, R., Minassian, A. M., .. Oxford COVID Vaccine Trial Group (2020). Safety and immunogenicity of the ChAdOx1 nCoV-19 vaccine against SARS-CoV-2: a preliminary report of a phase 1/2, single-blind, randomised controlled trial. Lancet (London, England), 396(10249), 467-478. https://doi.org/10.1016/S0140-6736(20)31604-4

Frater, J. L., Zini, G., d'Onofrio, G., \& Rogers, H. J. (2020, April 20). COVID - 19 e o laboratório de hematologia clínica. International Journal Of Laboratory Hematology, 42(S1), 11-18.

L Fu, E., Janse, R. J., de Jong, Y., HW van der Endt, V., Milders, J., van der Willik, E. M., de Rooij, E. N., Dekkers, O. M., Rotmans, J. I., \& van Diepen, M (2020, September 2). Lesão renal aguda e terapia de substituição renal em COVID-19: uma revisão sistemática e meta-análise. Clinical Kidney Journal, 550563.

Henry, B. M., Benoit, S. W., de Oliveira, M., Hsieh, W. C., Benoit, J., Ballout, R. A., Plebani, M., \& Lippi, G. (2020). Laboratory abnormalities in children with mild and severe coronavirus disease 2019 (COVID-19): A pooled analysis and review. Clinical biochemistry, 81, 1-8. https://doi.org/10.1016/j.clinbiochem.2020.05.012

Huang, I., Pranata, R., Lim, MA, Oehadian, A., \& Alisjahbana, B. (2020). Proteína C reativa, procalcitonina, dímero D e ferritina na doença coronavírus grave-2019: uma meta-análise. Avanços terapêuticos em doenças respiratórias. https://doi.org/10.1177/1753466620937175

Ji, W., Wang, W., Zhao, X., Zai, J., \& Li, X. (2020, January 22). Transmissão cruzada de espécies do coronavírus recém-identificado 2019-nCoV. Journal of medical virology, 433-440.

Kunutsor, S. K., \& Laukkanen, J. A. (2020, June 20). Manifestações hepáticas e complicações de COVID-19: uma revisão sistemática e meta-análise. journal of infection, 81(3), 72-74.

Li, Q., Guan, X., Wu, P., Wang, X., Zhou, L., Tong, Y., Ren, R., Leung, K., Lau, E., Wong, J. Y., Xing, X., Xiang, N., Wu, Y., Li, C., Chen, Q., Li, D., Liu, T., Zhao, J., Liu, M., Tu, W., ... Feng, Z. (2020). Early Transmission Dynamics in Wuhan, China, of Novel Coronavirus-Infected Pneumonia. The New England journal of medicine, 382(13), 1199-1207. https://doi.org/10.1056/NEJMoa2001316

Chao Li, Y., Zhu Bai, W., \& Hashikawa, T. (2020, February 27). O potencial neuroinvasivo de SARS-CoV2 pode desempenhar um papel na insuficiência respiratória de pacientes com COVID-19. journal of medical virology, 552-555.

Lima, Claudio Márcio Amaral de Oliveira. (2020). Informações sobre a nova doença coronavírus (COVID-19). Radiologia Brasileira, 53 (2), V-VI. Epub 17 de abril de 2020. https://doi.org/10.1590/0100-3984.2020.53.2e1

Madjid, MD, MS, M., Safavi-Naeini, MD, P., Solomon, MD, S. D., \& Vardeny, PharmD4, O. (2020, March 27). Efeitos potenciais dos coronavírus no sistema cardiovascular, uma revisão. jama cardiology, 5(7), 831-840.

Mahtani, K. R., Heneghan, C., \& Aronson, J. K. (2020, March 19). Quais são as evidências de distanciamento social durante pandemias globais? Um rápido resumo do conhecimento atual. Oxford COVID-19, 1-9.

Mao, L., Jin, H., Wang, M., Hu, Y., Chen, S., He, Q., Chang, J., Hong, C., Zhou, Y., Wang, D., Miao, X., Li, Y., \& Hu, B. (2020, April 10). Manifestações neurológicas de pacientes hospitalizados com doença do coronavírus de 2019 em Wuhan, China. jama neurology, 77(6), 683-690.

McIntosh, M. D., K. (2020, February). COVID-19: Epidemiologia, virologia e prevenção. Uptodate, 1-38.

Saúde, M. d. (2020). Boletim epidemiológico especial (36). secretaria de vigilância em saúde.

Nascimento, O. J. (2020). Complicações neurológicas associadas ao SARS-CoV-2 (COVID-19) no Brasil: Organização do grupo NEUROCOVID-RIO e achados preliminares. Revista Brasileira de Neurologia, 52(2), 05-09.

Gonçalves Ferreira Netto, R., \& do Nascimento Corrêa, J. W. (2020). EPIDEMIOLOGIA DO SURTO DE DOENÇA POR CORONAVÍRUS (COVID19). DESAFIOS - Revista Interdisciplinar Da Universidade Federal Do Tocantins, 7(Especial-3), 18-25. https://doi.org/10.20873/uftsuple2020-8710

Nunes, Michelle Darezzo Rodrigues, Pacheco, Sandra Teixeira de Araújo, Costa, Cícero Ivan Alcantara, Silva, Jaciane Alexandre da, Xavier, Welker da Silva, \& Victória, Juliana Zambrano. (2020). TESTES DIAGNÓSTICOS E CARACTERÍSTICAS CLÍNICAS DA COVID-19 EM CRIANÇAS: UMA REVISÃO INTEGRATIVA. Texto \& Contexto - Enfermagem, 29 , e20200156. Epub 12 de agosto de 2020. https://doi.org/10.1590/1980-265x-tce-2020-0156

Siemieniuk, R. A., Bartoszko, J. J., Ge, L., Zeraatkar, D., Izcovich, A., Kum, E., Pardo-Hernandez, H., Rochwerg, B., Lamontagne, F., Han, M. A., Liu, Q., Agarwal, A., Agoritsas, T., Chu, D. K., Couban, R., Darzi, A., Devji, T., Fang, B., Fang, C., Flottorp, S. A., ... Brignardello-Petersen, R. (2020). Drug treatments for covid-19: living systematic review and network meta-analysis. BMJ (Clinical research ed.), 370, m2980. https://doi.org/10.1136/bmj.m2980

Terpos, E., Ntanasis Stathopoulos, I., Elalamy, I., Kastritis, E., N. Sergentanis, T., Politou, M., Psaltopoulou, T., Gerotziafas, G., \& A. Dimopoulos, M. (2020, April 13). Achados hematológicos e complicações de COVID-19. American journal of hematology, 834-847.

Turci, M., Holliday, J., \& de Oliveira, N. (2020). A Vigilância Epidemiológica diante do Sars-Cov-2: desafios para o SUS e a Atenção Primária à Saúde. APS EM REVISTA, 2(1), 44-55. https://doi.org/10.14295/aps.v2i1.70

Zhang, W., Du, R. H., Li, B., Zheng, X. S., Yang, X. L., Hu, B., Wang, Y. Y., Xiao, G. F., Yan, B., Shi, Z. L., \& Zhou, P. (2020). Molecular and serological investigation of 2019-nCoV infected patients: implication of multiple shedding routes. Emerging microbes \& infections, 9(1), 386-389. https://doi.org/10.1080/22221751.2020.1729071

Xavier, Analucia R., Silva, Jonadab S., Almeida, João Paulo C. L., Conceição, Johnatan Felipe F., Lacerda, Gilmar S., \& Kanaan, Salim. (2020). COVID-19: manifestações clínicas e laboratoriais na infecção pelo novo coronavírus. Jornal Brasileiro de Patologia e Medicina Laboratorial, 56, e3232020. Epub July 01, 2020.https://doi.org/10.5935/1676-2444.20200049 
Research, Society and Development, v. 10, n. 6, e1210614872, 2021

(CC BY 4.0) | ISSN 2525-3409 | DOI: http://dx.doi.org/10.33448/rsd-v10i6.14872

Yan, Y., Shin, WI, Pang, YX, Meng, Y., Lai, J., You, C.,... Pang, CH (2020). Os primeiros 75 dias do novo surto de coronavírus (SARS-CoV-2): avanços recentes, prevenção e tratamento. Jornal Internacional de Pesquisa Ambiental e Saúde Pública, 17 (7), 2323. doi: 10.3390 / ijerph17072323

Zhang, W., Cheng, W., Luo, L., Ma, Y., Xu, C., Qin, P., \& Zhang, Z. (2020). Transmissão secundária da doença do coronavírus de pessoas pré-sintomáticas, China. Doenças infecciosas emergentes, 26 (8), 1924-1926. https://doi.org/10.3201/eid2608.201142

Zheng, Y., Ma, Y., Zhang, J., \& Xie, X. (2020, March 5). COVID-19 e o sistema cardiovascular. COVID-19 e o sistema cardiovascular, 17, 259-260.

Zhu, N., Zhang, D., Wang, W., Li, X., Yang, B., Song, J., Zhao, X., Huang, B., Shi, W., Lu, R., Niu, P., Zhan, F., Ma, X., Wang, D., Xu, W., Wu, G., Gao, G. F., Tan, W., \& China Novel Coronavirus Investigating and Research Team (2020). A Novel Coronavirus from Patients with Pneumonia in China, 2019. The New England journal of medicine, 382(8), 727-733. https://doi.org/10.1056/NEJMoa2001017

Liu, Z., Li, J., Wang, S., Chen, D., Zeng, W., Chen, S., Huang, Y., Huang, J., Long, W., Li, M., Gao, R., Guo, L., \& Wu, X. (2020, September 9). Associação dos níveis de procalcitonina com a progressão e prognóstico de pacientes hospitalizados com COVID-19. Int J Med Sci, 2468-2476.

Garg, M., Sharma, A. L., \& Singh, S. (2021, January). Avanço em biossensores para biomarcadores inflamatórios de SARS-CoV-2 durante 20192020. Biossensores e bioeletrônica, 171, 112703. https://doi.org/doi.org/10.1016/j.bios.2020.112703

Savio RD (2021). Procalcitonina (em COVID-19): The Incessant Quest. Jornal indiano de medicina intensiva: revista por pares, publicação oficial da Indian Society of Critical Care Medicine, 25 (1), 1-2. https://doi.org/10.5005/jp-journals-10071-23698

Zare, M. E., Wang, Y., Kansestani, A. N., Almasi, A., \& Zhang, J. (2020, December 18). A procalcitonina tem boa precisão para prognóstico de condição crítica e mortalidade em COVID-19: uma revisão sistemática e meta-análise da precisão do teste de diagnóstico. Iran J Allergy Asthma Immunol, 557-569. doi.org/10.18502/ijaai.v19i6.4926

Moreira, W. (2004). Revisão de Literatura e Desenvolvimento Científico: conceitos e estratégias para confecção (1st ed.). janus, lorena.

Mendes, K. D. S., Silveira, R. C. d. C. P., \& Galvão, C. M. (2008). Revisão integrativa: método de pesquisa para a incorporação de evidências na saúde e na enfermagem. Texto contexto - enferm, 17(4), 758-764. 